\title{
ABUNDÂNCIA E DISTRIBUIÇÃO ESPAÇO-TEMPORAL DOS CARANGUEJOS (CRUSTACEA: BRACHYURA) CAPTURADOS PELA PESCA INDUSTRIAL DO CAMARÃO-ROSA FARFANTEPENAEUS SUBTILIS (PÉREZ FARFANTE, 1967) NA PLATAFORMA CONTINENTAL DO AMAZONAS
}

\author{
Nóbrega, P.S.V. ${ }^{1,}{ }^{*}$; Brito, L.F. ${ }^{1,2}$, Martinelli-Lemos, J.M. ${ }^{1}$ \& Santos, C.R.M. ${ }^{3}$ \\ ${ }^{1}$ Universidade Federal do Pará (UFPA), Laboratório de Biologia Pesqueira e Manejo de Recursos Aquáticos. \\ ${ }^{2}$ Instituto Federal Instituto Federal de Educação, Ciência e Tecnologia do Pará (IFPA), Campus Belém. \\ ${ }^{3}$ Museu Paraense Emílio Goeldi, Departamento de Zoologia. \\ *Corresponding author: nobrega@ufpa.br
}

\begin{abstract}
Os crustáceos da infra-ordem Brachyura (caranguejos e siris) estão entre os principais invertebrados capturados como fauna acompanhante na pesca industrial de camarão em todo o mundo, contudo, informações ecológicas são escassas. O objetivo deste é estimar a abundância e distribuição espaço-temporal de Brachyura capturados incidentalmente pela pesca industrial do camarão-rosa Farfantepenaeus subtilis (Pérez Farfante, 1967) na Plataforma Continental do Amazonas (PCA). As coletas foram realizadas entre julho de 2015 a julho de 2016, sendo a fauna para análise selecionada após arrasto de fundo em embarcações da frota camaroeira. A área amostrada compreende bancos pesqueiros ao longo da PCA, situados entre as latitudes de $-0,05$ e $5 \mathrm{~N}$ as longitudes -49 e -46 W. A abundância foi representada pelo índice de Captura por Unidade de Esforço (CPUE), em grama por hora (g/h). Foram realizados 153 arrastos, totalizando 350,35 horas, com duração média de 3,29 h $( \pm 1,09$ h, desvio padrão). A profundidade variou de $35 \mathrm{~m}$ a $85 \mathrm{~m}$, com média de 54,28 m $( \pm 16,5)$. A maior abundância ocorreu em profundidades entre 60 a $80 \mathrm{~m}$, porém o maior número de arrastos foi entre 40 a $60 \mathrm{~m}$, o que demonstra a preferência do grupo pelas maiores profundidades. Foram identificados 6.333 braquiúros, pertencentes a 30 espécies e 10 famílias, sendo as mais representativas: Portunidae (9 espécies), Leucosiidae e Inachoididae (3 espécies cada). A maior frequência de ocorrência foi de Achelous rufiremus (Holthuis, 1959), totalizando 4.060 indivíduos (64,10\%), seguida de Callinectes ornatus Ordway, 1863 com 632 indivíduos (9,97\%) e Anasimus latus Rathbun, 1894 apresentando 608 indivíduos (9,60\%). Callinectes bocourti A. MilneEdwards, 1879 apresentou a maior CPUE (47,06 g/h), seguida de Calappa ocellata Holthuis, 1958 (32,18 g/h) e A. rufiremus com 29,05 g/h. Houve diferença significativa da CPUE ao longo dos meses $(p<0,05)$, sendo junho/julho os de maiores valores e fevereiro/março com os menores. Os pesqueiros de maior CPUE foram os popularmente conhecidos como "quarenta" (lat: entre 3,51 e 3,62; long: entre -48,4 e -50) e "25" (lat: entre 3,27 e 3,45; long: entre -48,05 e -49,46). A temperatura, salinidade e profundidade apresentam correlação significativa $(p<0,05)$ e positiva com a CPUE $(R=0,66 ; 0,49$ e 0,41 , respectivamente). Neste estudo verificouse a grande abundância, contribuição em biomassa e diversidade de braquiúros, os quais estão intimamente relacionados aos fatores ambientais analisados.
\end{abstract}

Palavras-chave: Amazônia, biodiversidade, captura incidental, fauna acompanhante.

Financiamento: CNPq, CEPNOR/ICMBio. 